\title{
Introduction
}

To the Bemba, millet porridge is not only necessary, but it is the only constituent of his diet which actually ranks as food .... I have watched natives eating roasted grain off of four or five maize cobs under my very eyes, only to hear them shouting to their fellows later, "Alas, we are dying of hunger ... We have not had a bite to eat all day."

-AUDREY RICHARDS, LAND, LABOUR, AND DIET IN NORTHERN RHODESIA, 1939

The importance of American foods in Africa is more obvious than in any other continent of the Old World, for in no other continent, except the Americas themselves, is so great a proportion of the population dependent on American foods. Very few of man's cultivated plants originated in Africa ... and so Africa has had to import its chief food plants from Asia and America .... As for the influence of these crops before 1850, we might hypothesize that the increased food production enabled the slave trade to go on as long as it did without pumping the black well of Africa dry.

-ALFRED CROSBY, THE COLUMBIAN EXCHANGE, 1972

Have the people of Africa always starved? Most people have never heard this question posed. So ingrained is the idea of "Africa" as a scarce place that the continent has become synonymous with need in popular thought. ${ }^{1}$ Preoccupied by images of hungry children and drought-ravaged landscapes, we have come to expect that we will find food insecurity in every time and place in the continent. But even the casual visitor to an African country observes something much different: people surviving despite the odds stacked against them. This book aims to challenge expectations of scarcity by investigating empirical realities of resilience 
in the culinary and agricultural history of Banda, a region of west-central Ghana that invokes an altogether different narrative of African food security.

The quotes above, both from pioneers in the study of food, index two different imaginaries of African food scarcity and reveal the crux of the challenge ahead. Audrey Richards (1995 [1939]) pioneered the study of foodways from an anthropological perspective, and her work remains an exemplar for its methodological sophistication. These methods allowed her to recognize that maize (corn) was not considered food to the Bemba, even if it met their caloric needs. This observation would be unremarkable except that it concerns Africans, who are often conceptually stripped of the ability to make choices about what they eat. People thought to be teetering on the edge of survival are rarely accorded the "luxury" of choice. This kind of mentality is clear in Alfred Crosby's conception of the Columbian Exchange. Maize, the same plant the Bemba eschewed in favor of indigenous grains, is accorded by him the role of savior in insuring sufficient calories for African bodies. Africans are portrayed as incapable of developing appropriate crops themselves. In contrast to Richards's empirically rich narrative, Crosby's synthesis provides no data to support his suppositions about Africa. We might justify Crosby's misdeeds as a thing of the past-he wrote The Columbian Exchange in the early 1970s, although a revised edition was published in 2003-and he was certainly no card-carrying Africanist. Yet many of his assumptions continue to haunt literature on the Columbian Exchange to this day (see chapters 2 and 3 ).

In this book, I argue that people in Banda were very much capable of feeding themselves in the centuries and millennia before Europeans took interest in the continent, and indeed afterwards, when livelihoods were reconfigured in the wake of Atlantic trade and colonialism. That this is not the story that is usually told about African peoples and places relates to the space between empirical realities and expectations of the continent, where implicit assumptions of a scarce Africa tend to go unquestioned. The goal of this book is to interrogate and ultimately repurpose this space into a critical zone of inquiry into African food history.

To introduce this endeavor, we need to consider why scarcity is the dominant paradigm through which we understand African foodways. To some the answer may seem obvious, since the highest prevalence of undernourishment in the world-one in five people-is found in the African continent. But to emphasize this statistic at the expense of the reverse-four in five people are not undernourished-acts to limit recognition of the tremendous ability of people to survive despite widespread poverty.

The tendency to view Africans in a negative light is unfortunately commonplace, and there is a large volume of scholarship that addresses and combats the oftentimes racist roots of these assumptions (e.g., Hammond and Jablow 1970; Mudimbé 1994; Pierre 2012). I build on this scholarship by exploring how these negative stereotypes infuse common (mis)understandings of food history and 
food security in the continent. Food-or lack thereof-provides one of the most powerful representations of scarce "Africa," for a multitude of reasons. We experience food viscerally, from pangs of hunger to feelings of satiety and flavors of novelty and delight. Food has direct, visible effects on the body, allowing estimates of caloric intake that underpin assumptions about economic status. Food is a requirement for life, and its absence reveals the stark inequalities that continue to exist today despite record high levels of food production on a global scale. Food is not an inconsequential or apolitical subject; what we say about food in print is both bound up in and contributes to misconceptions rooted in negative stereotypes about the continent, with very real consequences for food policy and development today (see chapter 6; Niemeijer 1996).

Understanding Africa's food history is imperative because it affords an interrogation of whether the scarcities observed today have always defined the continent. History helps us understand the ultimate causes of modern food security problems and the strategies used by people in the past to avert food disasters. Addressing these issues requires the use of alternative archives (Comaroff and Comaroff 1992, 34-35) that approach scarcity from the bottom up. Much like Richards's archive, the data I rely on are decidedly local, and include ethnography and oral histories. My study benefits from a deep-time perspective through the use of archaeology's rich record of everyday life. I weave these archives together to explore the food history of Banda, a locality in Ghana that has seen tremendous change and suggests even bigger possibilities. Banda's case study engenders a counternarrative of African food scarcity that ultimately questions how food security is managed on the continent. When outsiders expect to see scarcity, they have a hard time unseeing it. Food history allows us to see possibility and potential, with far-reaching impacts for how we might envision African futures.

\section{THE SCARCITY SLOT}

The driving force behind much environmental policy in Africa is a set of powerful, widely perceived images of environmental change . . So self-evident do these phenomena appear that their prevalence is generally regarded as common knowledge among development professionals in Afric[a] ... They have acquired the status of conventional wisdom ... Images of starving children, and the attribution of blame to natural environmental causes, have become an integral part of the way Africa is perceived in the North. They are signposts to the lie of the land: the reasoning behind them is taken for granted and rarely questioned.

- MELISSA LEACH AND ROBIN MEARNS, THE LIE OF THE LAND, 1996

Africanists have long concerned themselves with dismantling pervasive and tenacious stereotypes that define much outsider engagement with the continent and its peoples. Stereotypes tend to stand in for what is considered common knowledge 
in situations where people lack enough data to make an informed argument. These assumptions are often second nature and become implicit parts of peoples' ways of thinking or arguing. Even though common knowledge is often unsubstantiated, it remains difficult to debunk because of its pervasiveness, since ubiquity is often taken as an indication of obviousness (Keim 2014; Leach and Fairhead 1996; see also similar claims by Žižek 2008 regarding structural violence). Far from being self-evident, so-called common knowledge always comes from somewhere. In this section, I seek to understand how such generalizations are produced and reproduced. Zeroing in on knowledge production gives us the opportunity to disrupt the cycle of these remarkably tenacious stereotypes.

I refer to this collected conventional wisdom on African food and agriculture as the "scarcity slot." The scarcity slot both makes visible the process by which stereotypes are (re)produced and calls up a wide array of critiques from anthropology, geography, and history about misrepresentations of African food and agriculture. My position is that by naming these stereotypes and confronting them directly we may be in a better position to dislocate them. I build on Trouillot's (1991) notion of a "slot" to describe the tendency to fit new groups or information into predefined spaces or types. Slots are not constructed based on empirical realities. Their architecture is built and their contents filled through a process of Othering. The basic process involves comparison of the Self to the Other, with an assumption that the Other lacks a certain quality possessed by the Self (Said 2003). The resulting slot architecture functions to keep subject and object in the same structural position in order to "ensure a certain functioning of power" (Escobar 2012, 163). So long as power inequities exist, outsider imaginaries serve those who construct them rather than do justice to on-the-ground realities. Scholars are no exception, as they too are products of the privileges and prejudices of their time. As Trouillot (1991) outlines, anthropologists constructed an Other for the purposes of study through comparison to themselves, and archaeologists have been guilty of the same in Othering past peoples (Cobb 2005), especially in Africa (Lane 2005; Stahl 2005).

The content of slots changes over time as societies emphasize different priorities and as values and geopolitical relations evolve (Trouillot 1991, 33). While the savage slot outlined by Trouillot referenced sixteenth- to early twentieth-century notions of proper behavior and biopolitical relations between Europe and its colonies, in the late twentieth and early twenty-first century the Other has often been constructed according to notions of technological progress and resource availability (Escobar 2012, 144; Ong 1987). Along with water, food is the most essential of all resources, and thus food is central to the construction of the scarcity slot.

Throughout this book, I will critically examine three main tenets of the scarcity slot through empirical examination of culinary history in Ghana. These tenets are rooted in stereotypes that rely on assumptions of scarcity and build on earlier representations of "Africa" as a savage place. First, food is most often portrayed in reference to a lack of food, rather than in reference to local tastes or to the rich 
food traditions that have developed across the continent (Carney and Rosomoff 2009; La Fleur 2012). This mirrors Trouillot's (1991) observation that savages were often stripped of all manners and polite custom, which were conceptualized as the unique domain of Western elites. The second generalization is that African farmers tend to be portrayed as incapable of controlling seemingly hostile environments and as lacking agricultural expertise (Carney and Rosomoff 2009; La Fleur 2012; Richards 1985), making them especially vulnerable to environmental change (Ribot 2014); this is not dissimilar to the portrayal of savages as closer to nature (Trouillot 1991). Finally, African foodways and agriculture are often depicted as timeless and rooted in an unchanging past (Stump 2010). Savages too were placed in an earlier rung of the evolutionary ladder, displacing time and denying coevalness (Fabian 2002). In the remainder of this section, I expand on these assumptions and describe how this book aims to challenge each one.

\section{Tenet 1: Lack of Food}

During the Atlantic slave trade, Europeans knew where cereals were grown in West Africa as well as where to find food surpluses. But over the ensuing centuries of slavery, this knowledge was overlooked and seemingly lost; the enslavement of Africans dehumanized its victims and disparaged their achievements in agriculture and technology. The indigenous African cereals were viewed as nothing more than a few "inferior and miserable food staples."

—JUDITH CARNEY, BLACK RICE, 2001

Today, "Africa" is more often known for its alleged lack of food rather than for its bountiful agricultural resources. As Carney argues, this is a relatively recent view that is closely intertwined with pejorative views of Africans as inferior that emerged to justify the slave trade. In Black Rice, she documents how achievements in African rice cultivation were often attributed to Europeans, erasing centuries of knowledge and skill that were fundamental to the successful rice-based economies of West Africa as well as of the American South. Her exceptional work reveals how the Othering process can create vastly different views of a place or people to suit the needs of Europeans. Early European traders saw an abundance of food in Africa's ports; these observations were central to filling their very real needs for food but also to an image of Africa as plentiful and full of opportunities. As the Atlantic slave trade peaked in the eighteenth century, recasting Africans as inferior was a necessary worldview, and one that extended to their food and agricultural practices.

The content of these stereotypes has continued to evolve. Lack has been an important part of how the world's development experts have understood African food insecurity since at least the 1970s. The Sahel drought of 1968-1972 led to widespread famine and focused global attention on West Africa's food security needs. As Watts (2013) details, the crisis literature focused on lack of food supplies as the primary cause of famine. Experts linked food scarcity to increased 
risk of political instability under the emerging food security paradigm. Many of the resulting initiatives made a simple correlation between available food supplies and the prevalence of hunger. The solution seemed simple: produce more food through technological improvements. In the following decades, Africanist geographers and anthropologists pointed out the limitations of such a simple correlation. For example, Watts (2013) illustrates that chronic, seasonal hunger is much more prevalent than crisis events like famine. And Berry (1984) points to the difficulty in obtaining even basic estimates of agricultural production. If food supply cannot be measured, it is difficult to blame lack of food for Africa's food security woes, and this problem is compounded by the need to recognize smaller-scale but recurrent seasonal shortages (Watts 2013). Despite this empirical limitation, the idea that Africa needs to produce more food remains remarkably tenacious.

In the early 1980s, Amartya Sen used history to challenge the idea that food shortage was to blame for famine in India. His (1981) historical analyses of famines showed that in most cases, adequate food supplies were available, but were not distributed to those in need. Sen argued that the ultimate causes of famine have more to do with entrenched poverty, which is a historical product rather than a constant (chapter 1). The case study that is the focus of this book confirms this pattern. In the fifteen to seventeenth centuries, high levels of food security were maintained even during the worst drought in the last millennium, thanks to a strong local economy (chapter 2). It was only under conditions of privation born out of an emerging colonial global economy that chronic food insecurity emerged in the nineteenth century (chapter 4).

People perceived of as food insecure are often conceptually stripped of their ability to choose what is eaten, so it is not surprising that African tastes and food traditions are less often the subject of serious food study. More is written about French cuisine than the cuisines of all of Africa, a continent that is fifty-five times larger than France. The elevation of particular European cuisines, French chief among them, is rooted in colonial politics of value (Janer 2007). Jack Goody's (1982) Cooking, Cuisine, and Class inadvertently exacerbated the problem by making an explicit comparison between African food and that of Europe, effectively Othering African foodways into a non-European slot (see chapter 5). His main argument was that Africans lacked the haute cuisines found across Europe because they also lacked similarly pronounced class stratification. This thesis built on earlier work that argued that the different surplus potentials of African and Eurasian agriculture lead to more strongly stratified societies in the latter (Goody 1977). While this type of scholarship has fallen out of favor in anthropology, many of its assumptions and basic problems continue to beleaguer other fields, particularly economic history (e.g., Mayshar et al. 2015). As Africanists, the long afterlife of studies like Goody's should give us pause; while some of his work is still relevant, we have a responsibility to actively critique some of its more problematic aspects and offer alternative narratives. James McCann, the leading voice in African food 
history, attempts just that in his 2009 book, where he directly confronts Goody's stereotype of African foodways as mundane and undifferentiated by highlighting the range of culinary cultures across the continent as well as the skills of African women as cooks.

This book continues McCann's quest to illustrate the diversity and ingenuity of foodways across the continent, but takes aim specifically at assumptions of lack of food supplies. The perceived scarcity of modern-day African foodways is often extended to our understanding of past food choices, particularly in times and places when empirical data is scant. In this book, one of my major foci is the Columbian Exchange, long of interest to archaeologists and historians but less well attested in empirical records. The Columbian Exchange involved the movement of plants, animals, people, and diseases between hemispheres in the centuries following Columbus's arrival in the Americas, and represents one of the most significant changes in foodways in modern history (Crosby 2003). The introduction of the American staples maize and cassava to Africa has received a great deal of attention, since both crops are critical to maintaining food security in the present (e.g., Alpern 1992, 2008; McCann 2005; Miracle 1966). One hypothesis that has had remarkable staying power is that the introduction of maize made up for population losses suffered during the trans-Atlantic slave trade, since maize could produce higher yields and thus feed greater numbers of people. Originally formulated in the 1960 s by Crosby ([1972] 2003) and Curtin (1969), this hypothesis is based on highly suspect data and assumptions (see chapter 3 ). Yet theses like this endure, particularly outside of anthropology and history (e.g., Cherniwchan and Moreno-Cruz 2019), perhaps because they fit neatly into racialized assumptions about African resources and capabilities.

Recent Africanist food history has offered a different view of the Columbian Exchange by highlighting diverse African agencies during these tumultuous centuries. For example, scholars have shown how new foods like maize were actively employed in strategic ways by farmers and traders along the African coast (Carney and Rosomoff 2009; La Fleur 2012). I extend these works by arguing against assumptions of passivity that are central to the idea that Africans were in need of new foods, as the quote from Crosby that opened this chapter suggests. In Chapters 2-4, I attempt to evaluate whether such a need existed by looking at the adoption of American crops like maize. Like Carney (2001), I also recenter the important roles of African domesticates during the Columbian Exchange, by focusing on the contributions of pearl millet and sorghum, which have largely been overlooked by scholars focusing on this period.

Constructing an "Africa" that has always lacked food and food choices creates a terrain ripe for the expansion of development projects that assume lack of food is the problem to be solved (cf. Mitchell 2002). This worldview perpetuates the view that "Africa" needs outside help to solve its problems, and overlooks the homegrown solutions that may provide more sustainable ways forward. Used critically, 
the past provides a great potential source of data on strategies that helped people to weather environmental change in the past (Lane 2015; Logan et al. 2019). In chapter 2, I illustrate how local crops helped people persevere during the worst drought on record in the last millennium, and in chapter 6, I consider how these success stories can be used to reset the possibilities for the future.

\section{Tenet 2: Limited by Hostile Environments}

Knowledge of food-production [sic] and metals permitted concentrations of population, but slowly, for, except in Egypt and other favoured [sic] regions, Africa's ancient rocks, poor soils, fickle rainfall, abundant insects, and unique prevalence of disease composed an environment hostile to agricultural communities.

-JOHN ILIFFE, AFRICANS: THE HISTORY OF A CONTINENT, 1995

Their history was not just a shapeless mass of peoples' comings and goings, helpless before the vagaries of the environment.

-DAVId SCHOENBRUN, A GREEN PLACE, A GOOD PLACE, 1998

A strong environmental determinist bent has long permeated outsider approaches to Africa, with prominent scholars arguing that depauperate African environments explained the underdevelopment of the continent (e.g., Iliffe 1995; see Mandala 2005, 10 for a review; see chapter 3). Historians like David Schoenbrun responded by crafting well-supported rebuttals that show cases of clear agricultural abundance, innovation, and resilience. Key in these efforts is inserting African agencies into the equation, since environmental determinist formulations presuppose that African farmers were unable to overcome their inherited environmental limitations. Stereotypes like these have deep roots in racialized assumptions about the continent and its peoples, and take many forms, from assumptions about landscape degradation (Fairhead and Leach 1996; McCann 1999; see chapters 1 and 3) to assumptions about the roles of shifting agriculture and climate change (see excellent critiques by Berry 1993; Moore and Vaughan 1994; Ribot 2013; Richards 1985). At the root of these stereotypes is a process of Othering whereby European landscapes, agricultural practices, and environmental logics are compared to African ones.

Shifting cultivation is one of the clearest examples of this kind of Othering. Also known as slash-and-burn, the practice has been viewed with derision since at least the colonial era (and likely before, see chapter 3 ). This type of agricultural system involves clearance and burning of vegetation, farming the resulting plot for a year or two, and then moving to new plot until the former one regains fertility as natural vegetation regrows (Richards 1985, 49). To Europeans, shifting cultivation was wasteful since it required large quantities of land per unit population unlike the permanent, intensive fields they relied on at home (Moore and Vaughan 1994). These attitudes can be traced through some of the most influential 
scholarship on agricultural economics and more broadly, where they were assigned evolutionary significance. For example, Boserup (1965) saw the development of intensive systems as a function of population pressure, which she described as the driving force behind agricultural innovation. To her, shifting cultivation represented a surviving practice of a previous, less populous era (Richards 1985, 52-53).

At the root of this argument is the idea that population pressure and intensive agriculture represent universal progress (Richards 1985, 53). While intensive agriculture uses less land, it is far more demanding of labor. In the regions of tropical West Africa first encountered by Europeans, land was abundant and labor in short supply (Hopkins 1973), so there was no need to intensify production. We cannot assume that these dynamics have characterized the entire continent for all of time; rather, the land/population relationship needs to be approached as an empirical question. The trans-Saharan slave trade likely had a significant impact on portions of West and Central Africa, some of which were depopulated and therefore decreased the availability of labor and skill for agriculture (Carney and Rosomoff 2009; Inikori 1982). Indeed, European chroniclers noted labor shortages along the Gold Coast that were severe enough to create demand for imported slaves from elsewhere in the continent (La Fleur 2012; Lovejoy 2011). In these instances, there was no need for intensive agriculture in tropical West Africa; it was certainly not a "better" option, a perspective shared by the modern food movement that emphasizes low-tech, organic agriculture that is more environmentally sustainable than intensive, industrialized approaches.

Despite these cogent critiques, intensive agriculture (particularly of maize) continues to be regarded as the pinnacle of agricultural achievement among some food historians and archaeologists. The reasoning is that intensive agriculture enables the production of surplus, which can be used to support larger populations and accumulate wealth, which in turn enables the rise of civilizations (Goody 1977). Similar reasoning has been applied to explain the adoption of crops as part of the Columbian Exchange and the consequences of that adoption. Many Africanist historians and archaeologists assume that high-yielding crops like maize were adopted rapidly and enabled population growth, with some going so far as to credit American crops with the growth of state-level societies like Asante (chapter 3 ). Although this social evolutionary focus has been critiqued by Africanists for some time (e.g., McIntosh 1999; Stahl 1999a), the idea that intensive agriculture and surplus production were desirable has received less critical attention (but see Marshall and Hildebrand 2002; Richard 2017; Widgren 2017). Yet we should be cautious about applying what is essentially a Western economic rationale-and purported evolutionary benchmark-to precolonial African contexts, especially given the discussion of intensive agriculture above.

Despite these mitigating variables, African agriculture continues to be evaluated against Western yield-centric standards by some economic historians (see chapter 1 ). A brief example illustrates the problematic assumptions of such approaches. In 
one of the most recent case studies, Rönnbäck and Theodoris (2019) attempt to empirically evaluate historic agricultural productivity in Senegambia as compared to elsewhere in the world. They conclude that nineteenth-century Senegambian agricultural productivity was much lower than yields in nineteenth-century plantation economies in the United States. Yet the higher agricultural productivity of plantation production was built on the backs of enslaved Africans, many of whom were extracted from Senegambia. Labor has been a limiting factor in African agricultural communities, and this situation was likely worsened, or even created, by the siphoning off of agricultural laborers in their prime to be sold as captives in the Americas. The authors use these productivity gaps to argue that it was more profitable to sell Africans to European slave traders because their labor was more valuable in environments that afforded more productive agriculture. While this argument could certainly be deconstructed from a number of angles, what I want to take away from this discussion is that these kinds of questions were asked at all.

The persistence of arguments like these illustrates how badly we need to provincialize the idea that surplus and accumulation are universal priorities. In Provincializing Europe, Chakrabarty (2000) argues that Europe has tended to serve as the standard for the rest of the world, and he tasks scholars to treat it like any other place rather than like the pinnacle of human achievement. By this reasoning, surplus accumulation should be treated as an economic strategy used under a historically specific set of conditions rather than as an evolutionary benchmark (see also de Luna 2016). Many African agricultural strategies focus on risk reduction rather than high yields (Richards 1985). High-yielding intensive agriculture generally focuses on monocrops of singular species. These systems are particularly vulnerable to shortfalls in the specific needs of the focus crop (e.g., rainfall), and to diseases that prey on that species. In contrast, the multicropping strategies employed by many African subsistence farmers effectively disperse risk. "Because West African farmers tended to ride with, rather than override, natural diversity, it was assumed that their techniques were especially 'ancient' and 'primitive"” (Richards 1985, 42). What many European observers failed to grasp was that techniques like intercropping are much more appropriate to tropical environments, as the studies cited above demonstrate. The timing of rainfall onset in particular is highly variable in such environments, and can have devastating impacts on crop harvests. In this context, relying on monocrops would be catastrophic. While authors like Rönnbäck and Theodoris (2019) see these environmental constraints as limiting, an opposite interpretation could be offered. Combined with the ingenuity of African farmers, these constraints have created what is likely a more environmentally sustainable system.

Looking through an alternative lens, many Africanist scholars appreciate that the goals of African farmers may have been much different than those of their European contemporaries, that they have been at times rooted in different conceptions of wealth (Richard 2017; Stephens 2018a, 2018b). In some precolonial 
African economies, people and their skills sets were valued above the accumulation of material goods (Guyer and Belinga 1995; but see Stephens 2016). While we must be careful not to apply this model, devised for Central Africa, to the continent as a whole, it does provide an alternate conception of wealth that challenges some of the core assumptions of the dominant Western individual accumulation mentality, suggesting that there are multiple other ways in which people past and present have conceptualized wealth. Importantly for this study, the wealth-inpeople model evokes a very different strategy for food production and distribution, suggesting food sharing rather than surplus accumulation. In order to retain skilled followers, leaders would have had to feed them well. The ubiquity of highly developed craft specialists across precolonial African landscapes suggests that at least some locations may have produced enough surplus to feed the nonfarming populace (chapter 2). Regions that once adhered to a "subsistence ethic" that emphasized food distribution and sharing may have faced major changes under the transition to individualizing capitalist economies, with serious impacts on food security (chapter 4; Mandala 2005; Watts 2013).

Despite all of these complicating variables, many modern development projects encourage poor farmers to cultivate monocrops of high-yielding crops (e.g., see description of the One Acre Fund in Thurow 2012). The reasoning is that the increased surplus will allow farmers access to increased supplies of cash, which can then be used to invest in more land, animals, or other assets. This strategy derives from Western preconceptions about African agriculture, as well as from Eurocentric ideals of agriculture and surplus production. It goes against millennia of African farming innovations, including the development of systems that effectively manage environmental perturbations. Ultimately, a focus on high-yielding crops may leave African farmers more vulnerable (Logan 2017). Along with a growing number of Africanist archaeologists (e.g., Logan et al. 2019) I argue that we must look to the strategies farmers used in the past to cope with turbulence in order to develop alternative strategies for the future. Across the continent, Africans have dealt with a myriad of environmental, political, and economic changes, responding in innovative ways to the challenge of making ends meet. Archaeology is well suited to tracing these agricultural innovations and building usable pasts (Lane 2015; Stump 2010). Farmers have long found ways to produce more food when needed through processes of extensification or intensification, examples of which found in the past. Many of these African agricultural innovations were social (Guyer 1984; Logan and Cruz 2014; Stone, Netting, and Stone 1990) and they are usually overlooked by a value scheme that uses materialized technological advancements as benchmarks.

\section{Tenet 3: Timelessness}

Much writing about precolonial agriculture in Africa still suffers from "the ethnographic present tense." While reading works by historians, and also archaeologists, it is often difficult ... to discern between on the one hand 
assumptions based on ethnographic material, and on the other conclusions based on oral or written history or on archaeological results.

-MATS WIDGREN, "AGRICULTURAL INTENSIFICATION IN SUB-SAHARAN AFRICA, 1500-1800," 2017

The idea of "Africa" as static and unchanging is a remarkably tenacious stereotype that archaeologists, anthropologists, and historians have actively combated in the last several decades (e.g., Piot 1999; Stahl 2001; Stump 2010). Assumptions of timelessness continue to be extended to agriculture and foodways in particular (Freidberg 2003, 448; Goody 1982, 33), as Widgren laments. For example, throwaway statements about African farmers "toiling in a time warp, living and working essentially as they did in the 1930s," made by journalist Roger Thurow (2012, xix) appeal to a core set of Western beliefs about Africa and evidence little to no knowledge of past decades, much less centuries. This denial of modernity helps justify external interventions meant to "modernize" farmers stuck in the past. What these assumptions overlook is that the poverty they seek to alleviate through making Africans modern may well be the result of modernity itself (chapters 4-6).

Although we have a plethora of scholarship that attests to Africa's rich agricultural history, African food history is still in its early stages, and we lack a dedicated history of food security (chapter 1). Particularly for the nonspecialist, this gap creates the mirage that nothing has changed over time in terms of food scarcity and food practices (Freidberg 2003, 47-48). In this situation, some scholars "play fast and loose with time" (Stahl 2001, 20-27) referring to a "baseline" Africa to fill in informational gaps (Cobb 2005; Stahl 1993, 2001; Stump 2010; Trouillot 1995; Wylie 1985, 1989). This baseline "is composed of unexamined assumptions and empirical generalizations about a relatively unchanging Other before that threshold" (Cobb 2005, 563). One common baseline falls within the late precolonial or early colonial period (nineteenth to twentieth centuries), when written documentation first became available for many parts of Africa. Yet in the nineteenth century, West Africa was fraught with political troubles linked to shifts in global trade that often turned violent and resulted in food shortages (e.g., La Fleur 2012, 137-44; chapters 3 and 4 ). As a result, this period is hardly representative of the African past. Instead, knowledge should be based in evidence that is coterminous with the period in question (Stahl 1993, 249; Stahl 2001, 20-39), an approach I adopt when possible throughout this book (chapter 1).

The other baseline, as Widgren's remark suggests, is a somewhat ill-defined "ethnographic present," which might include everything from ethnohistoric and early anthropological sources from the late nineteenth and early twentieth centuries to ethnographic and ethnoarchaeological studies set in recent years. As I will show in subsequent chapters, the twentieth century was a time of dramatic change in food and agriculture, and we can document those changes since written and oral evidence is much more available than it is for prior periods. Widgren expresses frustration with this imagined ethnographic present in the context of 
his attempt to understand changes in land cover and agricultural strategies over the continent as a whole over the last millennium, as part of large-scale efforts to understand the Anthropocene across the globe. ${ }^{2}$ Information on farming in the "ethnographic present" is often uncritically interwoven into how archaeologists and historians characterize past agricultural practices, making it exceedingly difficult to reconstruct empirical agricultural histories. It also creates a false sense of continuity between present and past that begs a question: why is it permissible for scholars to conflate these very different contexts for food and agriculture?

Part of the answer lies in the ongoing production and reproduction of the scarcity slot. The timeless trope remains difficult to dislodge because temporal displacement is so central to how the West thinks of itself vis-à-vis Others. Inhabitants of the scarcity slot are depicted as "premodern," lacking the technology, infrastructure, and financial capacity of the "modern." Fabian $(2002,23)$ refers to this kind of knowledge production as relying on "Typological time" - a time which is measured not in linear years, but in socioculturally constructed binaries (i.e., traditional/modern). Different geographical locations thus are assigned different temporalities, with those practicing allegedly "traditional" behaviors assumed to be survivals of an earlier time, while only those with "modern" habits are allowed to occupy the present. This tendency is what Fabian (2002) refers to as the denial of coevalness, or contemporaneity, with the so-called moderns. This view assumes that history is unidirectional and progressive, silencing processes of decay and slow violence. The lack of written histories in many of the areas designated as traditional exacerbates this temporal displacement, by creating the mirage that if histories are not written down and easily accessible, they simply do not exist (Stahl 2001; Wolf 1982). These forms of temporal displacement lead to the misconception that scarcity is a permanent state of being rather than a result of historical processes (Logan 2016a; Stahl 1993, 249-50).

One of the major goals of this book is to highlight the flawed evidentiary basis upon which these three major received understandings are based, as well as their origins (see chapter 4). This critique impels a revised narrative of scarcity and African food history. We need a different set of assumptions when approaching culinary history in the continent, some of which have already been outlined by recent work on African food history (Carney and Rosomoff 2009; La Fleur 2012; McCann 2005, 2009). These works forefront African agency and ingenuity, and in so doing, decenter the primary role that Europeans have written for themselves in the history of the continent.

\section{ORGANIZATION OF THE BOOK}

In order to develop a counternarrative to the scarcity slot, this book tells a tale of one place and how it has been defined by both scarcity and abundance at different points in its history. Banda, in west-central Ghana (map 1), provides the 


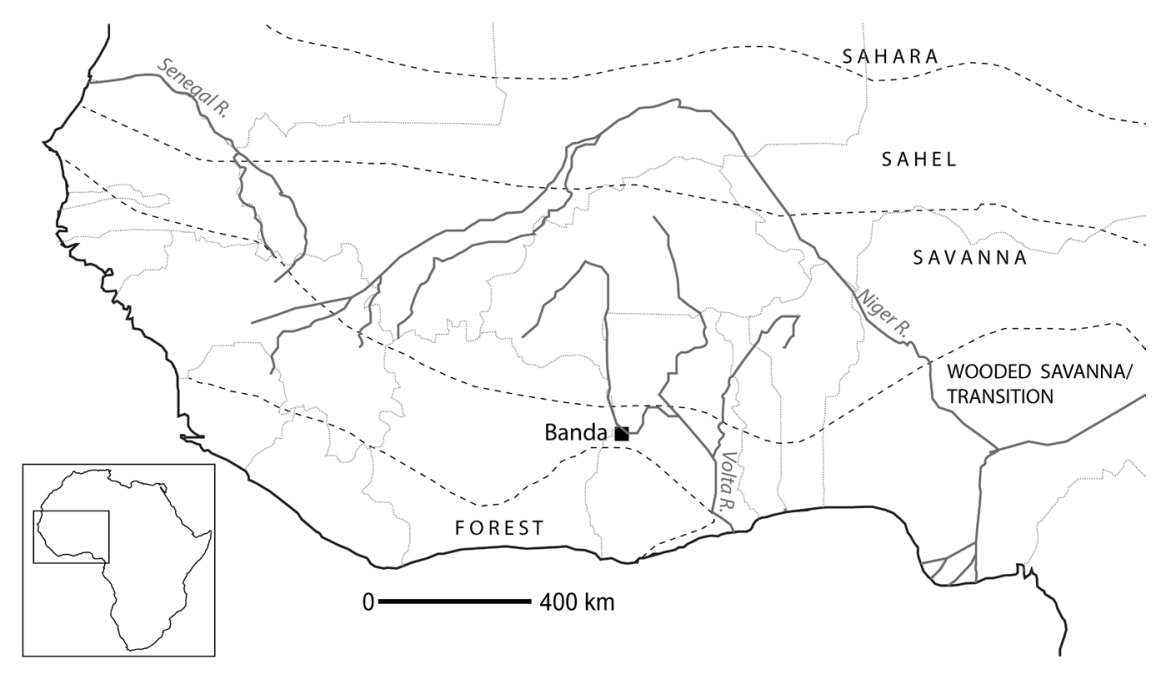

MAP 1. Location of the Banda region within West Africa, showing bioclimatic zones.

ideal case study because it has been the focus of nearly four decades of sustained archaeological and historical research, which has documented the challenges and opportunities afforded by shifting political economic and environmental conditions (Stahl 1999b, 2001, 2007). In 1500, Banda was home to large, bustling towns whose trade tentacles stretched across the premodern world system, and to a strong economy that enabled people to survive the worst drought in a millennium (map 2). Five centuries later, the same town is still vibrant, but occupies a much different position in the world order, and has lost some of the resilience to environmental change observed in the past. Viewing this place over time, we can see potential that multiple forces of history have eroded. This narrative challenges the lens of timelessness and backwardness through which Africa is usually imagined.

In chapter 1, I begin this journey by considering another kind of scarcity that has defined African food history: a lack of traditional source material, which has had a marked impact on how we perceive and write about food scarcity in the past. Food historians studying other locations rely on a creative array of written records as diverse as recipe cards, advertisements, poetry, and ancient imperial policies on adulteration. Unfortunately, this reliance on written sources privileges food stories from parts of the world with long traditions of literacy (e.g., China, Egypt, the Near East, Europe; e.g., Albala 2014). As a consequence, vast areas of the world, including sub-Saharan Africa, are not subject to the kind of critical food history that is needed to debunk stereotypes and build alternative food narratives. Africanist historians and anthropologists have long struggled with the same kinds of challenges, and have developed creative solutions for writing African history that inform my approach to food. Building on these insights, in chapter 1 I advance a longue durée history of food security as a corrective to the scarcity slot. 


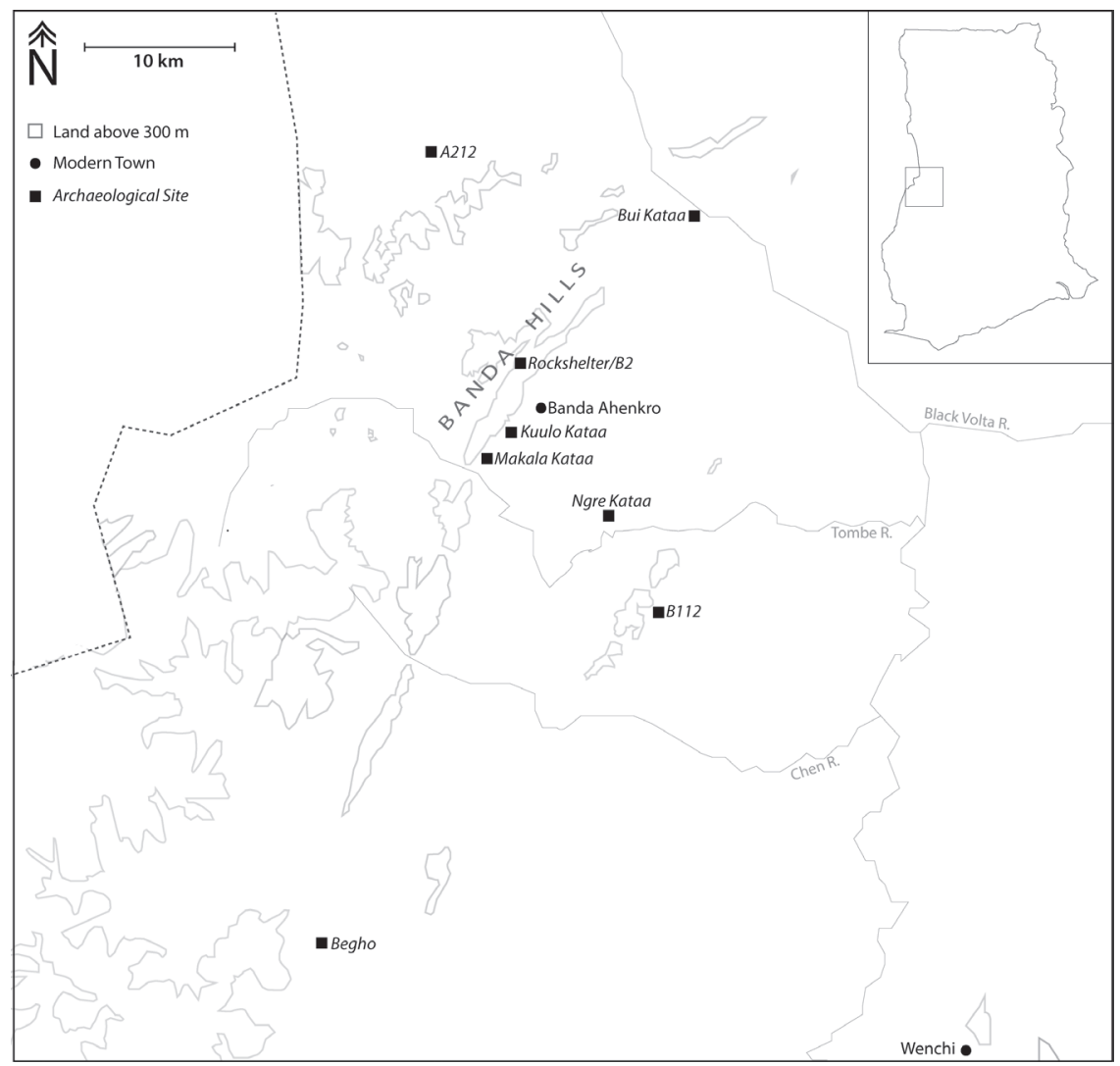

MAP 2. Archaeological sites in the Banda region discussed in text.

While studies of modern-day food security abound, we lack a devoted study of the history of food scarcity and abundance across the continent. From modern studies, we know that food security is not simply a function of how much food is produced, since food supplies are rarely distributed equitably across society. These studies encourage us to pay attention to food access and how it has changed over time. I offer a brief survey of how agricultural, economic, and environmental history hints at major changes in food production and access over the last several thousand years in order to provoke a series of empirical questions for an emergent history of food security over the long term.

Chapter 1 also details my methodological intervention into crafting African food history. I refer to this approach as excavation, building from the basic principles of archaeological excavation. Stratigraphy, or the layers of soil deposited over time, helps us establish chronological control at most sites around the world. We collect artifacts from each layer, comparing them to one another in an attempt to understand contemporaneous events, and to layers above and below in order to 
grasp change over time. In much the same way, I adhere to a temporal scaffolding to discuss the case study that is central to this book, in order to highlight change over time rather than to apply insights from one period to another uncritically.

The next four chapters tack back and forth between stereotypes about African food writ large and Banda's specific food history over the last six hundred years. This format allows me to illustrate how empirical data from one small place can be used to debunk broader stereotypes about the continent. The stereotypes I choose to critique represent the most pervasive ideas about African food in their respective periods. Rather than trace the genealogies of these ideas-an important task I must leave to future works-I focus on presenting empirical evidence that challenges their core assumptions. This is a deliberate stylistic choice meant to devote the bulk of the book to constructing an alternative narrative based on archaeological and historical evidence and minimizing the oftentimes quite conjectural arguments that have dominated discussions of these periods. In other words, I seek to decenter outsider assumptions and genealogies and center the choices and experiences of African farmers and cooks.

Chapters 2 and 3 are direct critiques of specific misconceptions about the introduction of American crops as part of the Columbian Exchange. In chapter 2, I tackle the notion that Africans were in need of new high-yielding crops from the Americas at the time of their arrival on the continent. To do so, I rely on archaeological data to evaluate the impact of the Columbian Exchange and severe drought in Banda (c. 1400-1650), with emphasis on the introduction of American staple crops like maize. This chapter highlights Banda's potential to weather environmental crises, highlighting the often ignored role of African political economies and indigenous food crops in mitigating drought. The resulting narrative challenges the notion that scarcity has always defined foodways throughout the continent, instead emphasizing culinary preference and choice.

Maize has been accorded a central role in the rise of the Asante state, as well as curative powers in alleviating the low population densities created by the Atlantic slave trade. Using archaeological and historical data, chapter 3 investigates foodways during the height of the Asante empire and Atlantic slave trade, taking the reader from the rich feasts of Asante nobles to the everyday foods of its subjects to the extreme deprivations suffered by those in captivity. This spectrum of food choice highlights the diverse experiences of different African actors during the eighteenth and nineteenth centuries, providing an important counternarrative to views of African food as a simple calories-in-calories-out equation.

Chapter 4 addresses major debates about the impact of colonial interventions on African food security and poverty. Some see colonial interventions as having had little effect on already food-insecure Africans, while others argue that colonial policies utterly transformed Africa's food landscape. I detail Banda's experiences in the late nineteenth and early twentieth centuries. Although not subject to direct agricultural policy interventions, archaeological and oral historical data 
suggest severe food security challenges during this time, particularly an increasingly severe hungry season. This tumultuous period is often used as a baseline by which to understand African food history, so it is no wonder that scarcity remains an enduring presumption. A longue durée view helps us see that this period and its pronounced food insecurity was in many ways an outlier.

In Chapter 5, I examine the relationship between hunger and modernity in postcolonial times (1940s-2009) based on ethnographic interviews. Readers unfamiliar with West African foodways may choose to start with this chapter before reading the historical narrative, to gain an appreciation for the taste preferences and common preparations that define modern African food (or refer to OsseoAsare 2005, which provides a more comprehensive overview of modern West African food). Instead of providing a primer on African food for the uninitiated, I decided to situate modern foodways in historical space, since they are products of the historical narrative told in the first few chapters of this book. Rather than adopting a chronological focus, chapter 5 highlights the tensions between hunger and modernity in how Banda cooks and farmers make, grow, and abandon foods. Many of these tensions center upon the demands placed on women as cooks, farmers, and mothers, as well as upon the interplay of technology, markets, and aspirations. Rather than using the "ethnographic present" as a means to understand archaeological contexts, I instead consider recent times on their own terms, as products of an ever-changing relationship with the past.

I further explore recent tensions in chapter 6, which opens with an account of the Olden Times Food Fair I organized in Banda in 2014. Heritage foods tend to be viewed negatively in contemporary Banda, because of who makes them and their association with tradition and poverty. These views are rooted not only in local experiences but also in global portrayals of Africa as a scarce, backward place. The forgetting of histories like the one told in this book is rooted in colonial socialities that continue to define modern geopolitical relationships, with real implications for how food security is approached and managed. Remembering those pasts is critical to decolonizing the future. 